\title{
Determination of Load Equivalency for Unpaved Roads
}

\author{
Xiaohui Sun, Jie Han, Mark H. Wayne, Robert L. Parsons, \\ and Jayhyun Kwon
}

\begin{abstract}
The load equivalency method is widely used to consider the effect of traffic loading on pavement design, and the equivalent axle load factor (EALF) for paved roads has been studied often. For unpaved roads, however, EALF is not well understood because it is not necessarily the same as it is for paved roads. In this study, cyclic plate load tests were conducted on unpaved road sections (six base-over-subgrade sections and four subgrade-only sections) constructed in a geotechnical box $(2 \mathrm{~m} \times 2.2 \mathrm{~m} \times 2 \mathrm{~m})$ to investigate the load equivalency for unpaved roads. The base-over-subgrade sections were constructed as unstabilized, T1 geogrid-stabilized, and T2 geogrid-stabilized base courses of $15 \%$ California bearing ratio (CBR) with thicknesses of $0.23 \mathrm{~m}$ and $0.30 \mathrm{~m}$ over weak subgrade of $2 \%$ CBR. The subgrade-only sections were constructed with CBR values of $6.2 \%, 7.4 \%, 9.5 \%$, and $11.0 \%$. The intensities of the cyclic loads were increased from $5 \mathrm{kN}$ to $65 \mathrm{kN}$, at increments of $5 \mathrm{kN}$. For each load intensity, 100 cycles were applied on one test section. The EALFs were analyzed in terms of permanent deformation. The results showed that the regression powers of the ratios of axle loads for unpaved roads with aggregate bases over weak subgrade ranged from 1.9 to 2.9, which were lower than a power of 4 , the typical value used for paved roads. The powers for subgrade-only sections had an even wider range, from 1.1 to 3.4. The increase of base thickness, the presence of geogrid, and the use of a higher-grade geogrid increased the power.
\end{abstract}

In pavement design, traffic loading is the most important and complex parameter because of the variety of the loading magnitude, configuration, and number of load repetitions $(1,2)$. There are two major procedures for considering traffic loading in pavement design. In the 1993 edition of AASHTO's Guide for Design of Pavement Structures, traffic loads with different load magnitudes or configurations are converted to equivalent numbers of a standard axle load, usually the 18-kip $(80-\mathrm{kN})$ single-axle load, in terms of the destructive effect of the load, that is, equivalent axle load factor (EALF) (3). In the Mechanistic-Empirical Pavement Design Guide (MEPDG) (4), the traffic load is considered individually by inputting the axle load spectra, so there is no need to assign an equivalent factor for each axle load (5). Compared with the load

X. Sun, J. Han, and R. L. Parsons, Department of Civil, Environmental, and Architectural Engineering, University of Kansas, 1530 West 15th Street, Lawrence, KS 66045. M. H. Wayne and J. Kwon, Tensar International, 2500 Northwinds Parkway, Suite 500, Alpharetta, GA 30009. Corresponding author: J. Han, jiehan@ku.edu.

Transportation Research Record: Journal of the Transportation Research Board, No. 2473, Transportation Research Board of the National Academies, Washington, D.C., 2015, pp. 233-241.

DOI: 10.3141/2473-27 spectra method used in the MEPDG, for which a computer program is needed to evaluate the response of the pavement under different traffic load, the load equivalency method is simple, convenient, and still widely used in the design of paved or unpaved roads. The Giroud and Noiray method is one such design method (6).

The EALF of a particular type of vehicle $j$ is defined as follows (7):

$\mathrm{EALF}=\frac{d_{j}}{d_{s}}=\frac{N_{f s}}{N_{f j}}$

where

$$
\begin{aligned}
d_{j}= & \text { damage per pass of vehicle } j \\
d_{s}= & \text { damage per pass of a standard vehicle, } \\
N_{f s}= & \text { number of repetitions to failure due to the load of a standard } \\
& \text { vehicle, and } \\
N_{f j}= & \text { number of repetitions to failure due to the load of vehicle } j .
\end{aligned}
$$

In this definition, the accumulation of the damage per pass of vehicle $j$ is assumed to be the same. In other words, the damage per pass of vehicle $j$ is assumed to be linear with the number of repetitions of the vehicle, even though there is evidence that indicates this is not necessarily true (8). Two common failure criteria considering the critical state of the tensile strain at the bottom of asphalt layer $\left(\varepsilon_{t}\right)$ and the vertical permanent strain at the top of subgrade $\left(\varepsilon_{c}\right)$ were chosen in flexible pavement design as Equations 2 and 3 (2).

$N_{f j}=f_{1}\left(\varepsilon_{t}\right)^{-f_{2}}\left(E_{1}\right)^{-f_{3}}$

$N_{f j}=f_{4}\left(\varepsilon_{c}\right)^{-f_{5}}$

where $f_{1}, f_{2}, f_{3}, f_{4}$, and $f_{5}$ are regression parameters and $E_{1}$ is the elastic modulus of the asphalt layer. By assuming both strains proportional to axle loads, EALFs based on the two-failure criteria can be expressed in the same formula, Equation 4.

$\mathrm{EALF}=\frac{N_{f s}}{N_{f j}}=\left(\frac{L_{j}}{80}\right)^{n}$

where $L_{j}$ is the magnitude of the axle load of vehicle $j$ in kilonewtons and $n$ is the power term, $f_{2}$ or $f_{5}$, which is identified as 4 by AASHTO and the corresponding formula known as the fourth-power law.

Deacon et al. studied the influence of the subgrade modulus and the surface modulus on the EALF based on fatigue distresses in flexible pavements (1). Their results showed that the EALFs were only slightly affected by the subgrade moduli but significantly influenced by the surface moduli. 
Dawson showed that the value of the power was material specific and increased with the increase of subgrade moisture content (8). Additionally, Dawson pointed out that the existence of a threshold stress above which large deformations developed rapidly made it difficult to establish a fixed load-equivalency relationship. Buhari and Puteh noted that the power $n$ in Equation 4 was dependent on several factors, including vehicle speed, axle type, load configuration, and damage mechanism (9). Lin et al. conducted load tests on one newly constructed freeway, and their results indicated that the AASHTO method yielded reliable predictions of EALF (10). Alabaster et al. showed that the damages during the initial shakedown period and after the initial shakedown period did not accumulate at the same rate, and they suggested the potential use of two equivalent single-axle load equations with different exponents (11). Yeo reported similar findings in which the power law exponents during the second stage of rutting were between 2.0 to 4.4 (12).

As the previous discussion indicates, the load equivalency for flexible pavements has been studied for decades. Tingle and Jersey note, however, that the majority of the world's roads are unpaved and for those roads, the EALF not yet well understood (13). Hence, it is important to study the load equivalency for unpaved roads. In real design, as shown in Equation 4, the EALF for a certain axle load $\left(L_{j}\right)$ can be calculated if the power $n$ is available and $N_{f j}$ can be converted subsequently to $N_{f s}$, a significant parameter in pavement design, with the computed EALF. Investigating the power $n$ in order to obtain the EALF for unpaved roads is therefore necessary.

In this study, ten cyclic plate load tests with increasing magnitudes of loads were conducted on unpaved test sections to backcalculate the powers $n$ in Equation 4 with respect to the performance criterion of the permanent strain. In the ten test sections, six test sections were constructed as base courses over weak subgrade and four test sections were constructed only with subgrade material at different CBRs. The surface permanent deformations and subgrade permanent deformations were monitored by displacement transducers. The effects of the base course thickness, the stabilized condition by geogrid, and the subgrade CBR on the backcalculated $n$ were investigated.

\section{TEST MATERIALS}

\section{Base Course}

Well-graded AB-3 aggregate, commonly used for low-volume roads in Kansas, was chosen as the study's base course material. Compaction tests were conducted to obtain the dry densities of the samples corresponding to different moisture contents and to determine the optimum moisture content with the modified Proctor compaction method (ASTM D1557). The CBR test was conducted on each sample obtained in the compaction test (ASTM D1883). The compaction and CBR curves of this material are shown in Figure 1. The average CBR value of the base material in the test sections was controlled at approximately $15 \%$ by compacting the material at a moisture content of $7.3 \%$.

\section{Subgrade}

As pointed out by Dell'Acqua et al., the use of low-bearing materials, such as clay and silt, and local resources is an important way to simplify and economize road construction (16). In this study, an artificial soil obtained by mixing $75 \%$ Kansas River sand and $25 \%$ kaolin with water by weight served as the subgrade material. Figure 2 shows the compaction and CBR curves, which were obtained with the standard Proctor compaction method (ASTM D1557). In the test sections of base courses over weak subgrade, the subgrade material was compacted at a moisture content of $10.8 \%$ to achieve a CBR of approximately $2 \%$. In the test sections of subgrade, the moisture content of the material was adjusted to achieve CBR values ranging from approximately $5 \%$ to $10 \%$.

\section{Geogrid}

Two types of triaxial geogrid were used in this study: a light-grade duty (T1) and a heavy-grade duty (T2). The properties of the geogrid are shown in Table 1.

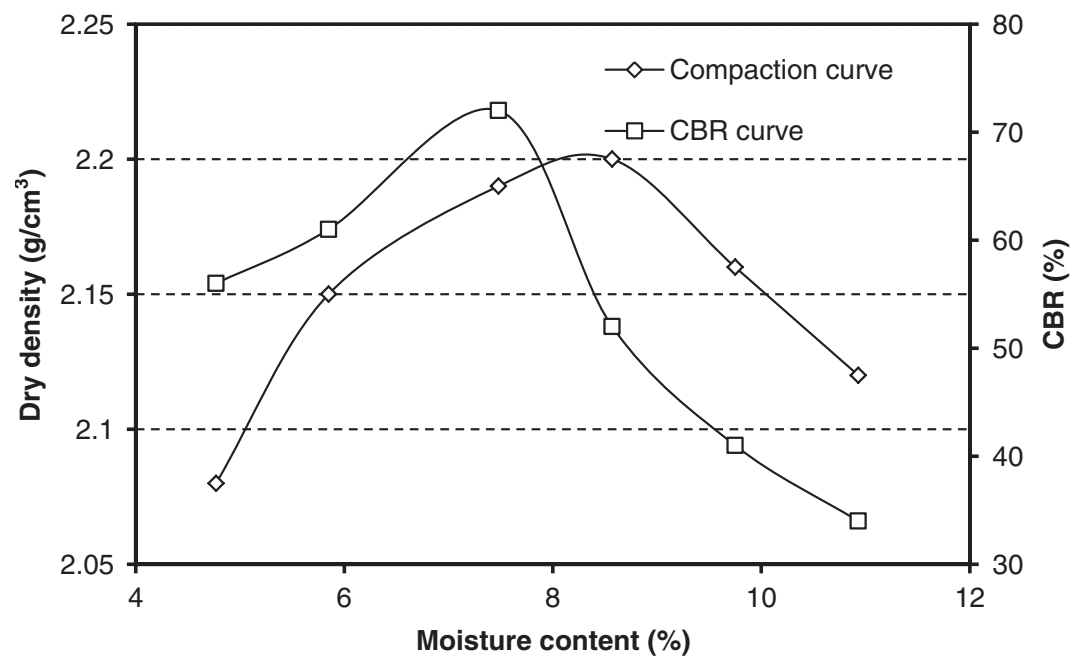

FIGURE 1 Compaction and CBR curves of base course material $(14,15)$. 


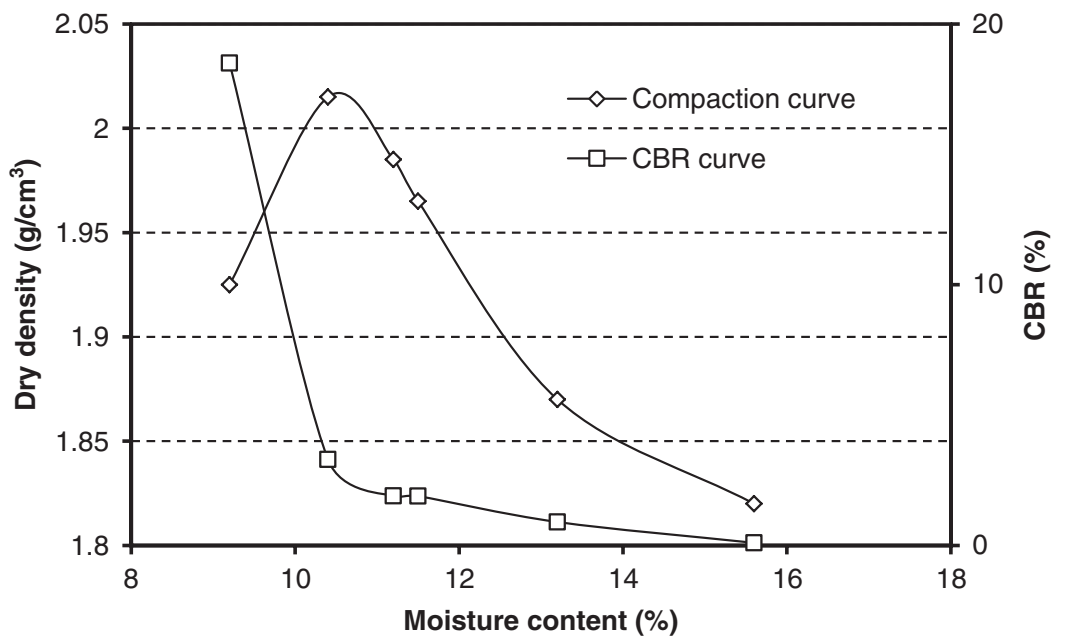

FIGURE 2 Compaction and CBR curves of subgrade material (15).

\section{TEST SETUP}

Ten cyclic plate load tests were conducted in a geotechnical box $(2 \mathrm{~m} \times 2.2 \mathrm{~m} \times 2 \mathrm{~m})$ at the University of Kansas. Six tests were conducted on unstabilized and geogrid-stabilized (i.e., T1 and T2) base courses $(0.23 \mathrm{~m}$ thick and $0.30 \mathrm{~m}$ thick) over weak subgrade, and four tests were performed on 1-m-thick subgrade at different CBRs. The geogrid, if used, was placed at the interface of the base course and the subgrade. The test setup of this study is shown in Figure 3.

The surface deformations were measured by displacement transducers set at the center of the loading plate. The subgrade deformation was monitored by a telltale device (connected to a displacement transducer) seated at the top of the subgrade, as shown in Figure 3.

The intensities of the loads applied on a steel loading plate of $0.30 \mathrm{~m}$ in diameter were increased from $5 \mathrm{kN}$ to $65 \mathrm{kN}$, with each load increment at $5 \mathrm{kN}$, as shown in Figure 4. One hundred loading cycles were applied on a test section at each loading stage; the testing would stop, however, if the accumulated permanent deformation reached $80 \mathrm{~mm}$. By gradually increasing the load magnitude, aggregate was further compacted without exhibiting shakedown behavior.

\section{TEST RESULTS AND DISCUSSIONS}

\section{Dynamic Cone Penetration Tests}

Dynamic cone penetration tests were performed at four locations in each test section of this study. Figure 5 shows the results of the average dynamic cone penetration index (DCPI, in millimeters).

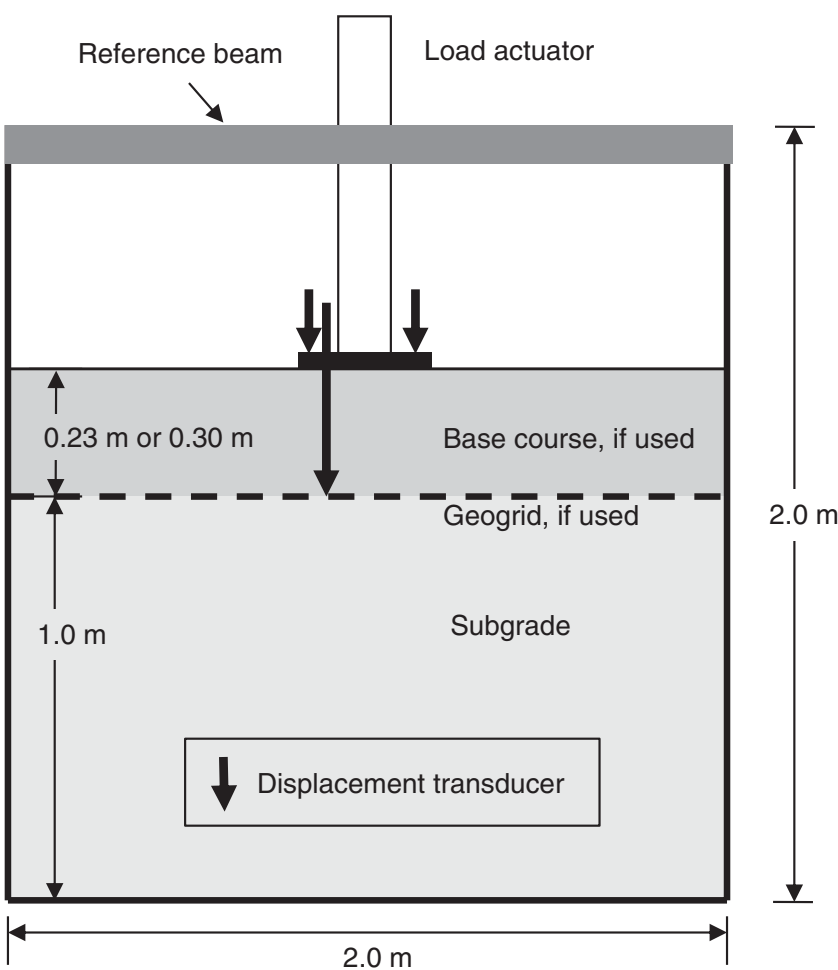

FIGURE 3 Test setup.

TABLE 1 Properties of Triaxial Geogrids Used in Study

\begin{tabular}{llcllll}
\hline Geogrid Type & $\begin{array}{l}\text { Rib Pitch, } \\
\text { Longitudinal (mm) }\end{array}$ & $\begin{array}{l}\text { Rib Pitch, } \\
\text { Diagonal }(\mathrm{mm})\end{array}$ & $\begin{array}{l}\text { Middepth, } \\
\text { Diagonal (mm) }\end{array}$ & $\begin{array}{l}\text { Middepth, } \\
\text { Transverse (mm) }\end{array}$ & $\begin{array}{l}\text { Midwidth, } \\
\text { Diagonal (mm) }\end{array}$ & $\begin{array}{l}\text { Midwidth, } \\
\text { Transverse (mm) }\end{array}$ \\
\hline T1 & 40 & 40 & 1.3 & 1.2 & 0.9 & 1.2 \\
T2 & 40 & 40 & 2.0 & 1.6 & 1.0 & 1.3 \\
\hline
\end{tabular}




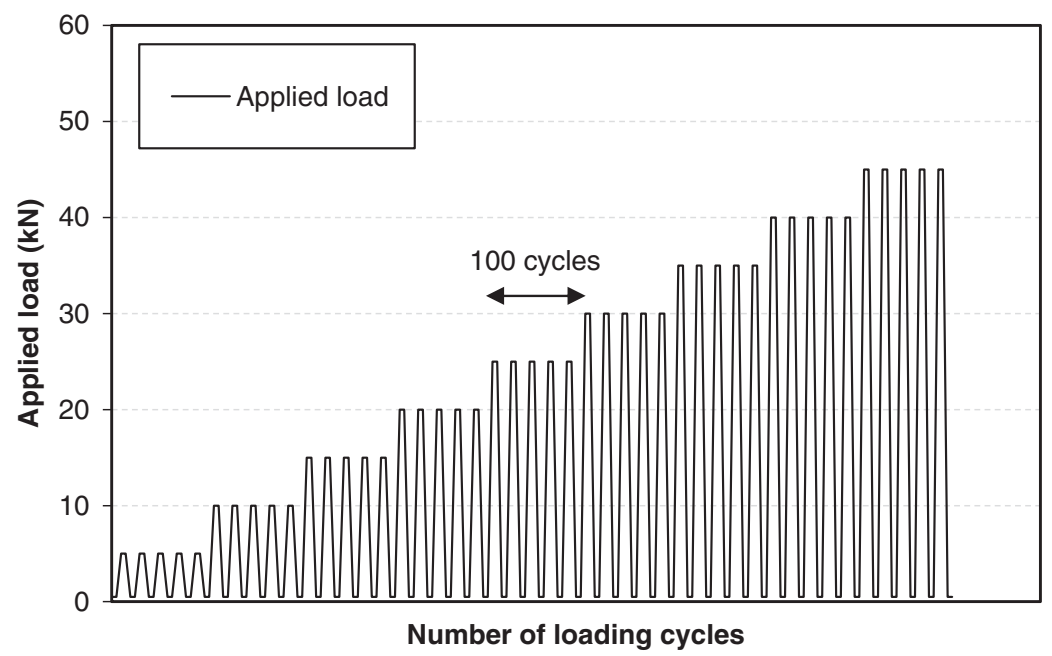

FIGURE 4 Loading intensities.

The CBR value at each location was calculated by Equation 5 (17), and the test results are summarized in Table 2 .

$\mathrm{CBR}=\frac{292}{(\mathrm{DCPI})^{1.12}}$

\section{Permanent Deformations}

As mentioned previously, the permanent deformation on the top of the subgrade was selected as one failure criterion for paved roads. In this study, both the surface permanent deformation and the subgrade permanent deformation were chosen as the performance criteria.

The permanent deformations of all the test sections were monitored by displacement transducers, and the initial value of the permanent deformation was set to zero at the beginning of each loading stage. The criteria of permanent deformations were set as $4 \mathrm{~mm}$, $6 \mathrm{~mm}, 8 \mathrm{~mm}$, and $10 \mathrm{~mm}$ to consider the destructive effect of each load intensity. For the test sections with a base course, the numbers of loading cycles applied under each load intensity to induce the surface and subgrade permanent deformations up to the permanent deformation criteria are summarized in Tables 3 and 4. For the test sections of subgrade at different CBR values, the numbers of loading cycles applied under each load intensity to reach the same permanent deformation criteria are provided in Table 5.

With the same permanent deformation, the number of loading cycles decreased with the increase of the load intensities, as shown in Tables 3, 4, and 5. This result indicated that the destructive effects of loads were enhanced. The presence of the geogrid and the increase of the base course thickness increased the number of loading cycles in terms of the same surface and subgrade permanent deformations. Table 5 shows similar results with the increase of the CBR value of the subgrade material.

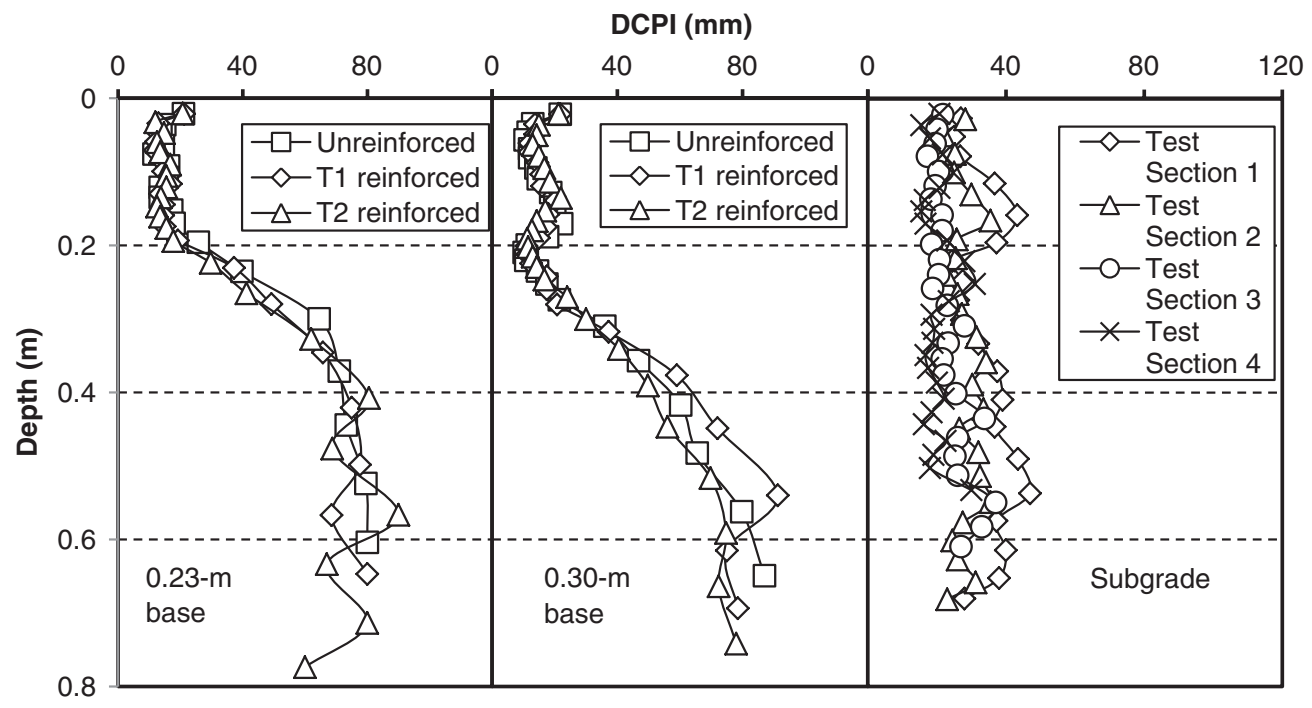

FIGURE 5 Dynamic cone penetration tests of base course over subgrade. 
TABLE 2 Average CBR Values of Different Test Sections

\begin{tabular}{lllc}
\hline & & \multicolumn{2}{l}{ CBR Value (\%) } \\
\cline { 3 - 4 } Test Section & Stabilization Type & Subgrade & Base Course \\
\hline 0.23-m-thick base course over subgrade & Unstabilized & 2.3 & 14.2 \\
& T1 geogrid & 2.4 & 15.4 \\
& T2 geogrid & 2.3 & 14.9 \\
0.30-m-thick base course over subgrade & Unstabilized & 2.3 & 15.2 \\
& T1 geogrid & 2.3 & 14.8 \\
Test Section 1 & T2 geogrid & 2.4 & 14.5 \\
Test Section 2 & na & 6.2 & na \\
Test Section 3 & na & 7.4 & na \\
Test Section 4 & na & 9.5 & na \\
\hline
\end{tabular}

NoTE: na = not applicable.

\section{Regression of the Power $n$}

For a standard single-axle load of $80 \mathrm{kN}$, the standard wheel load is $40 \mathrm{kN}$, which can be simulated by a load applied on a steel plate. Based on data in Tables 3, 4, and 5, the EALF of each wheel load intensity can be calculated by Equation 4 . Hence, the value of the power $n$ in Equation 4 can be regressed because the $L_{j} / 80$ is known for each EALF, where $L_{j}$ is the single-axle load of vehicle $j$. Figures 6 and 7 show the EALF versus $L_{j} / 80$ for the test sections with base courses over weak subgrade in terms of the surface permanent deformation. In Figure 6, the data are divided into two groups on the basis of base course thickness. The regressed $n$ value for the test section with a 0.23 -m-thick base course is 2.01 , and for the test section with a 0.30 -m-thick base course, the regressed $n$ value is 2.88. These results indicate that the increase of the base thickness increases the power $n$. The overall value of the regressed power $n$ is 2.28. In Figure 7, the data points are grouped into three categories: unstabilized, T1 geogrid-stabilized, and T2 geogrid-stabilized. The

TABLE 3 Loading Cycles to Reach Same Surface Deformation Under Different Load Intensities, by Base Course Thickness

\begin{tabular}{|c|c|c|c|c|c|c|c|c|c|c|}
\hline \multirow[b]{2}{*}{ Stabilization Type } & \multirow{2}{*}{$\begin{array}{l}\text { Permanent } \\
\text { Deformation } \\
(\mathrm{mm})\end{array}$} & \multicolumn{9}{|c|}{ Number of Loading Cycles, by Single Wheel Load } \\
\hline & & $10 \mathrm{kN}$ & $15 \mathrm{kN}$ & $20 \mathrm{kN}$ & $25 \mathrm{kN}$ & $30 \mathrm{kN}$ & $35 \mathrm{kN}$ & $40 \mathrm{kN}$ & $45 \mathrm{kN}$ & $50 \mathrm{kN}$ \\
\hline \multicolumn{11}{|c|}{ Base Course Thickness $=0.23 \mathrm{~m}$} \\
\hline \multirow[t]{4}{*}{ Unstabilized } & 4 & NA & 45 & 31 & 27 & 20 & 13 & $12^{a}$ & NA & NA \\
\hline & 6 & NA & NA & 65 & 45 & 25 & 20 & $14^{a}$ & NA & NA \\
\hline & 8 & NA & NA & 99 & 67 & 43 & 26 & $20^{a}$ & NA & NA \\
\hline & 10 & NA & NA & NA & 72 & 57 & 35 & $27^{a}$ & NA & NA \\
\hline \multirow[t]{4}{*}{$\mathrm{T} 1$ geogrid } & 4 & NA & 65 & 49 & 36 & 26 & 19 & 10 & NA & NA \\
\hline & 6 & NA & NA & 95 & 74 & 49 & 29 & 16 & NA & NA \\
\hline & 8 & NA & NA & NA & NA & 67 & 39 & 26 & NA & NA \\
\hline & 10 & NA & NA & NA & NA & 95 & 50 & 33 & NA & NA \\
\hline \multirow[t]{4}{*}{ T2 geogrid } & 4 & NA & NA & 87 & 55 & 43 & 31 & 21 & 14 & NA \\
\hline & 6 & NA & NA & NA & 92 & 68 & 48 & 32 & 22 & NA \\
\hline & 8 & NA & NA & NA & NA & 97 & 66 & 44 & 30 & NA \\
\hline & 10 & NA & NA & NA & NA & NA & 86 & 56 & 38 & NA \\
\hline \multicolumn{11}{|c|}{ Base Course Thickness $=0.30 \mathrm{~m}$} \\
\hline \multirow[t]{4}{*}{ Unstabilized } & 4 & NA & NA & NA & 66 & 53 & 33 & 22 & 13 & NA \\
\hline & 6 & NA & NA & NA & NA & 62 & 39 & 27 & 19 & NA \\
\hline & 8 & NA & NA & NA & NA & 80 & 54 & 36 & 25 & NA \\
\hline & 10 & NA & NA & NA & NA & NA & 80 & 46 & 33 & NA \\
\hline \multirow[t]{4}{*}{$\mathrm{T} 1$ geogrid } & 4 & NA & NA & NA & 81 & 48 & 30 & 21 & 15 & NA \\
\hline & 6 & NA & NA & NA & NA & 81 & 47 & 33 & 24 & NA \\
\hline & 8 & NA & NA & NA & NA & NA & 65 & 45 & 31 & NA \\
\hline & 10 & NA & NA & NA & NA & NA & 90 & 58 & 39 & NA \\
\hline \multirow[t]{4}{*}{$\mathrm{T} 2$ geogrid } & 4 & NA & NA & NA & 92 & 65 & 34 & 28 & 21 & 15 \\
\hline & 6 & NA & NA & NA & NA & NA & 66 & 44 & 32 & 21 \\
\hline & 8 & NA & NA & NA & NA & NA & 95 & 65 & 44 & 30 \\
\hline & 10 & NA & NA & NA & NA & NA & NA & 88 & 56 & 38 \\
\hline
\end{tabular}

Note: NA = not available.

${ }^{a}$ Data obtained by the fitting curve. 
TABLE 4 Loading Cycles to Reach Same Subgrade Deformation Under Different Load Intensities

\begin{tabular}{|c|c|c|c|c|c|c|c|c|}
\hline \multirow[b]{2}{*}{ Stabilization Type } & \multirow{2}{*}{$\begin{array}{l}\text { Permanent } \\
\text { Deformation } \\
(\mathrm{mm})\end{array}$} & \multicolumn{7}{|c|}{ Number of Loading Cycles, by Single Wheel Load } \\
\hline & & $20 \mathrm{kN}$ & $25 \mathrm{kN}$ & $30 \mathrm{kN}$ & $35 \mathrm{kN}$ & $40 \mathrm{kN}$ & $45 \mathrm{kN}$ & $50 \mathrm{kN}$ \\
\hline \multicolumn{9}{|c|}{ Base Course Thickness $=0.23 \mathrm{~m}$} \\
\hline Unstabilized & 4 & 63 & 40 & 27 & 15 & $11^{a}$ & NA & NA \\
\hline & 6 & NA & 68 & 42 & 25 & $21^{a}$ & NA & NA \\
\hline & 8 & NA & NA & NA & NA & NA & NA & NA \\
\hline & 10 & NA & NA & NA & NA & NA & NA & NA \\
\hline T1 geogrid & 4 & 76 & 62 & 41 & 26 & 15 & NA & NA \\
\hline & 6 & NA & NA & 58 & 39 & 23 & NA & NA \\
\hline & 8 & NA & NA & 75 & 53 & 31 & NA & NA \\
\hline & 10 & NA & NA & 100 & 68 & 38 & NA & NA \\
\hline $\mathrm{T} 2$ geogrid & 4 & 96 & 78 & 62 & 41 & 26 & 19 & NA \\
\hline & 6 & NA & NA & NA & 66 & 47 & 31 & NA \\
\hline & 8 & NA & NA & NA & 93 & 65 & 42 & NA \\
\hline & 10 & NA & NA & NA & NA & NA & NA & NA \\
\hline \multicolumn{9}{|c|}{ Base Course Thickness $=0.30 \mathrm{~m}$} \\
\hline \multirow[t]{4}{*}{ Unstabilized } & 4 & NA & NA & 52 & 32 & 21 & 15 & NA \\
\hline & 6 & NA & NA & 87 & 49 & 32 & 23 & NA \\
\hline & 8 & NA & NA & NA & 67 & 44 & 30 & NA \\
\hline & 10 & NA & NA & NA & 89 & 56 & 39 & NA \\
\hline \multirow[t]{4}{*}{ T1 geogrid } & 4 & NA & NA & 69 & 37 & 27 & 17 & NA \\
\hline & 6 & NA & NA & NA & 59 & 41 & 27 & NA \\
\hline & 8 & NA & NA & NA & 83 & 57 & 37 & NA \\
\hline & 10 & NA & NA & NA & 100 & 75 & 47 & NA \\
\hline \multirow[t]{4}{*}{ T2 geogrid } & 4 & NA & NA & 78 & 53 & 37 & 27 & 19 \\
\hline & 6 & NA & NA & NA & 75 & 56 & 42 & 29 \\
\hline & 8 & NA & NA & NA & NA & 82 & 58 & 40 \\
\hline & 10 & NA & NA & NA & NA & $100^{a}$ & 75 & 50 \\
\hline
\end{tabular}

NotE: NA = not available.

${ }^{a}$ Data obtained by the fitting curve.

TABLE 5 Loading Cycles to Reach Same Surface Deformation Under Different Load Intensities, by CBR

\begin{tabular}{|c|c|c|c|c|c|c|c|c|c|c|}
\hline \multirow{2}{*}{$\begin{array}{l}\text { Permanent } \\
\text { Deformation } \\
(\mathrm{mm})\end{array}$} & \multicolumn{10}{|c|}{ Number of Loading Cycles, by Single Wheel Load } \\
\hline & $20 \mathrm{kN}$ & $25 \mathrm{kN}$ & $30 \mathrm{kN}$ & $35 \mathrm{kN}$ & $40 \mathrm{kN}$ & $45 \mathrm{kN}$ & $50 \mathrm{kN}$ & $55 \mathrm{kN}$ & $60 \mathrm{kN}$ & $65 \mathrm{kN}$ \\
\hline \multicolumn{11}{|l|}{$\mathrm{CBR}=6.2 \%$} \\
\hline 4 & 61 & 38 & 27 & 23 & 22 & 19 & 18 & NA & NA & NA \\
\hline 6 & NA & 70 & 45 & 38 & 35 & 30 & 28 & NA & NA & NA \\
\hline 8 & NA & NA & 69 & 55 & 50 & 42 & 39 & NA & NA & NA \\
\hline 10 & NA & NA & 100 & 76 & 67 & 56 & 51 & NA & NA & NA \\
\hline \multicolumn{11}{|l|}{$\mathrm{CBR}=7.4 \%$} \\
\hline 4 & NA & 58 & 45 & 35 & 37 & 28 & 24 & NA & NA & NA \\
\hline 6 & NA & NA & 88 & 66 & 61 & 47 & 41 & NA & NA & NA \\
\hline 8 & NA & NA & NA & NA & 86 & 68 & 58 & NA & NA & NA \\
\hline 10 & NA & NA & NA & NA & NA & NA & NA & NA & NA & NA \\
\hline \multicolumn{11}{|l|}{$\mathrm{CBR}=9.5 \%$} \\
\hline 4 & NA & NA & 78 & 53 & 41 & 34 & 33 & 30 & NA & NA \\
\hline 6 & NA & NA & NA & 97 & 69 & 57 & 54 & 39 & NA & NA \\
\hline 8 & NA & NA & NA & NA & $111^{a}$ & 89 & 71 & 60 & NA & NA \\
\hline 10 & NA & NA & NA & NA & NA & NA & NA & NA & NA & NA \\
\hline \multicolumn{11}{|l|}{$\mathrm{CBR}=11.0 \%$} \\
\hline 4 & NA & NA & NA & NA & 75 & 44 & 30 & 22 & 18 & 14 \\
\hline 6 & NA & NA & NA & NA & $117^{a}$ & 78 & 48 & 34 & 28 & 22 \\
\hline 8 & NA & NA & NA & NA & $158^{a}$ & NA & 70 & 49 & 38 & 30 \\
\hline 10 & NA & NA & NA & NA & $200^{a}$ & NA & 96 & 64 & 49 & 38 \\
\hline
\end{tabular}

NoTE: NA = not available.

${ }^{a}$ Data obtained by the fitting curve. 


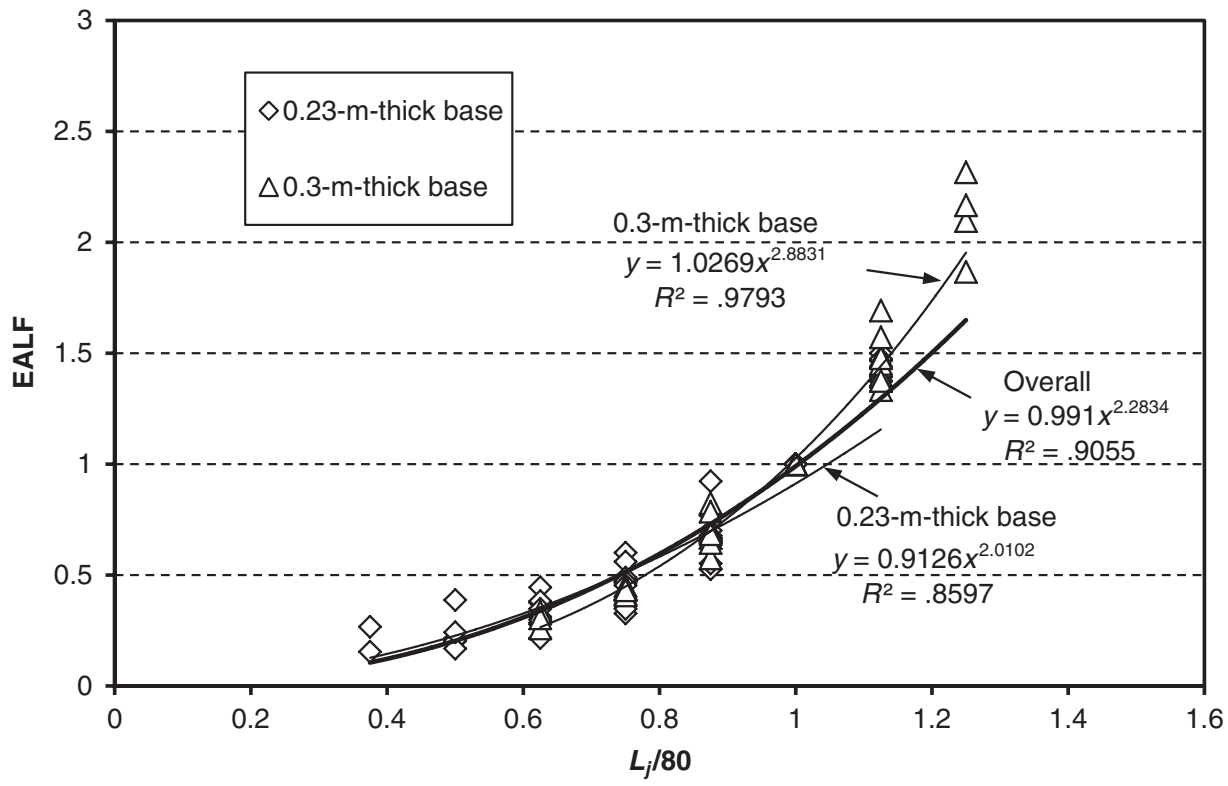

FIGURE 6 EALF versus $L_{j} / 80$ for test sections with different base thicknesses in terms of surface permanent deformation.

regressed powers $n$ for the three groups are 1.94, 2.42, and 2.53, respectively. These results indicate that the presence of the geogrid and the use of the higher-grade geogrid increase the power $n$.

Figures 8 and 9 show the EALF versus $L_{j} / 80$ for the test sections with base courses over weak subgrade in terms of the subgrade permanent deformation. Similar trends of the regressed power $n$ are presented in Figures 8 and 9 as compared with those in Figures 6 and 7, but the values of the power in terms of the subgrade permanent deformation are larger than those in terms of the surface permanent deformation.

Figure 10 shows the EALF versus $L_{j} / 80$ for the test sections of subgrade at different CBRs. With the increase of the subgrade CBR from $6.2 \%$ to $11.0 \%$, the regressed power $n$ increases from 1.12 to 3.44. The correlation between the regressed power $n$ versus the CBR of the subgrade material can be expressed as Equation 6.

Power $n=0.2775 \mathrm{e}^{0.2152 \mathrm{CBR}}$

For the unpaved roads with or without a base course, the power $n$ is generally lower than 4 (a typical value used for design of flexible pavements). The base thickness, the reinforcement type, and the CBR of the material influence the power $n$. As noted in the study by Deacon et al. (1), the increase of the surface modulus increases the power $n$. For the test sections of subgrade at different CBRs, the increase of the CBR means the increase of the surface modulus.

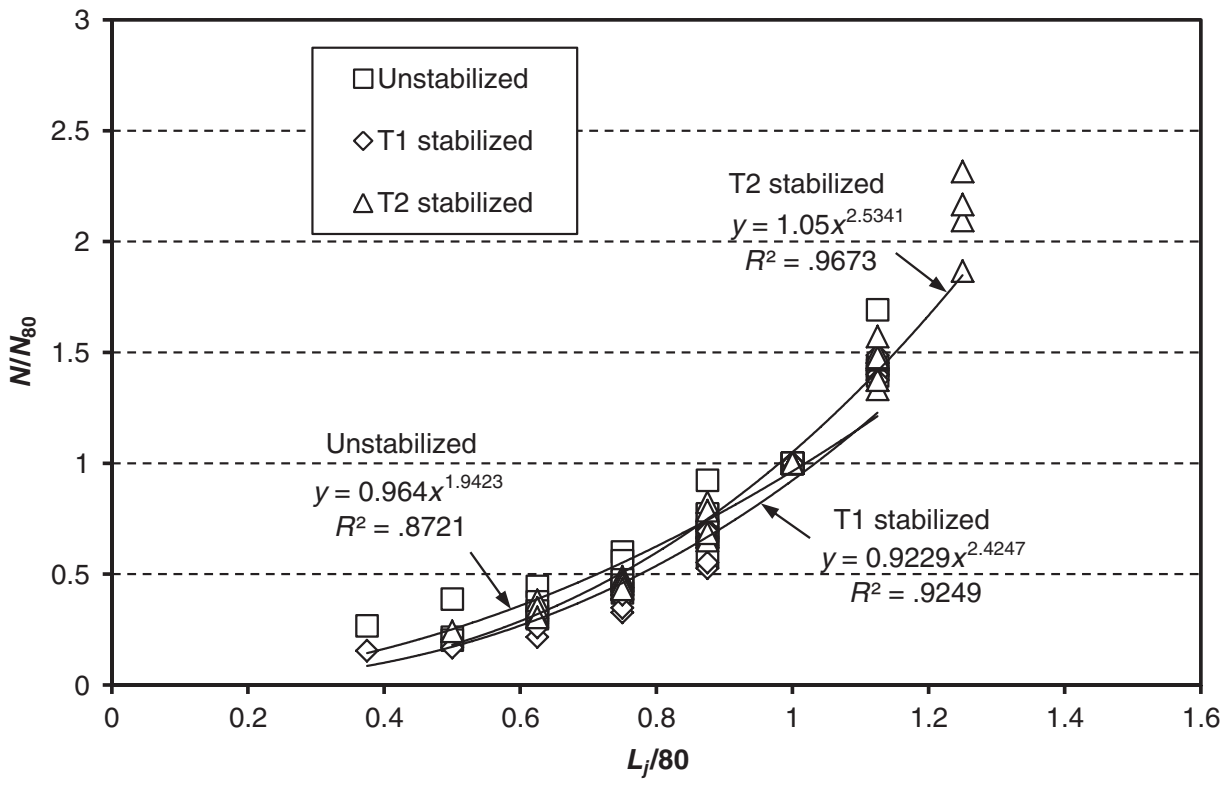

FIGURE 7 EALF versus $L_{j} / 80$ for test sections with different reinforcement types in terms of surface permanent deformation ( $N=$ number of cycles). 


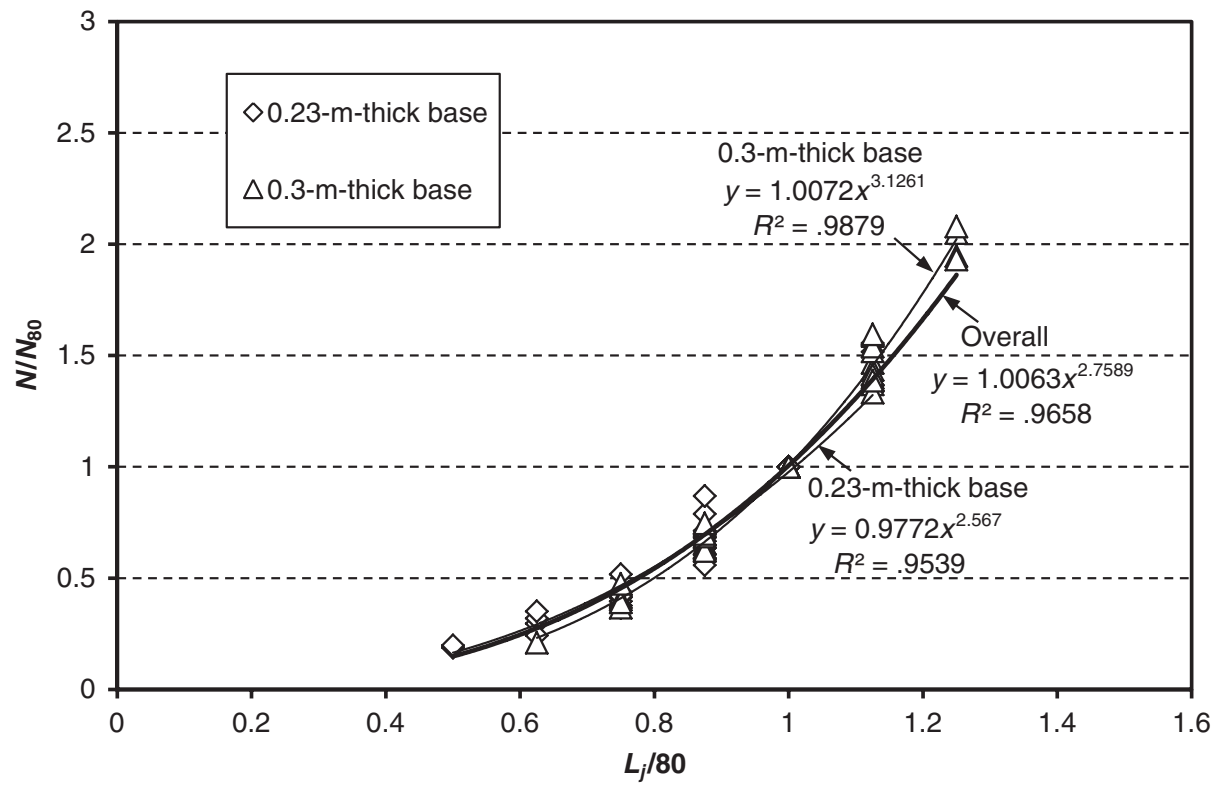

FIGURE 8 EALF versus $L_{j} / 80$ for test sections with different base thicknesses in terms of subgrade permanent deformation.

Moreover, the increase of the base course thickness, the presence of the geogrid, and the use of the higher-grade geogrid can increase the equivalent modulus of the base course as well. The trend of the regressed power $n$ in this study is therefore reasonable.

\section{CONCLUSIONS}

This study adopted a load increment approach to increase the load. At each increment of loading, a fixed number of cycles was used. The EALFs were calculated on the basis of loads at different magnitudes and generated the same permanent deformations of
4 to $10 \mathrm{~mm}$. With the calculated EALFs, the powers $n$ of EALFs for subgrade-only, unstabilized, and geogrid-stabilized bases over weak subgrade were determined. These powers may vary if actual conditions are different from those used in this study. The following conclusions from this study can be made:

1. The powers $n$ of EALFs for the unpaved roads at different permanent deformations were lower than 4 (the typical value used for flexible pavements).

2. The powers $n$ of EALFs for the base courses (15\% CBR) of different thickness over weak subgrade $(2 \% \mathrm{CBR})$ with or without geogrid stabilization based on the surface permanent deformations

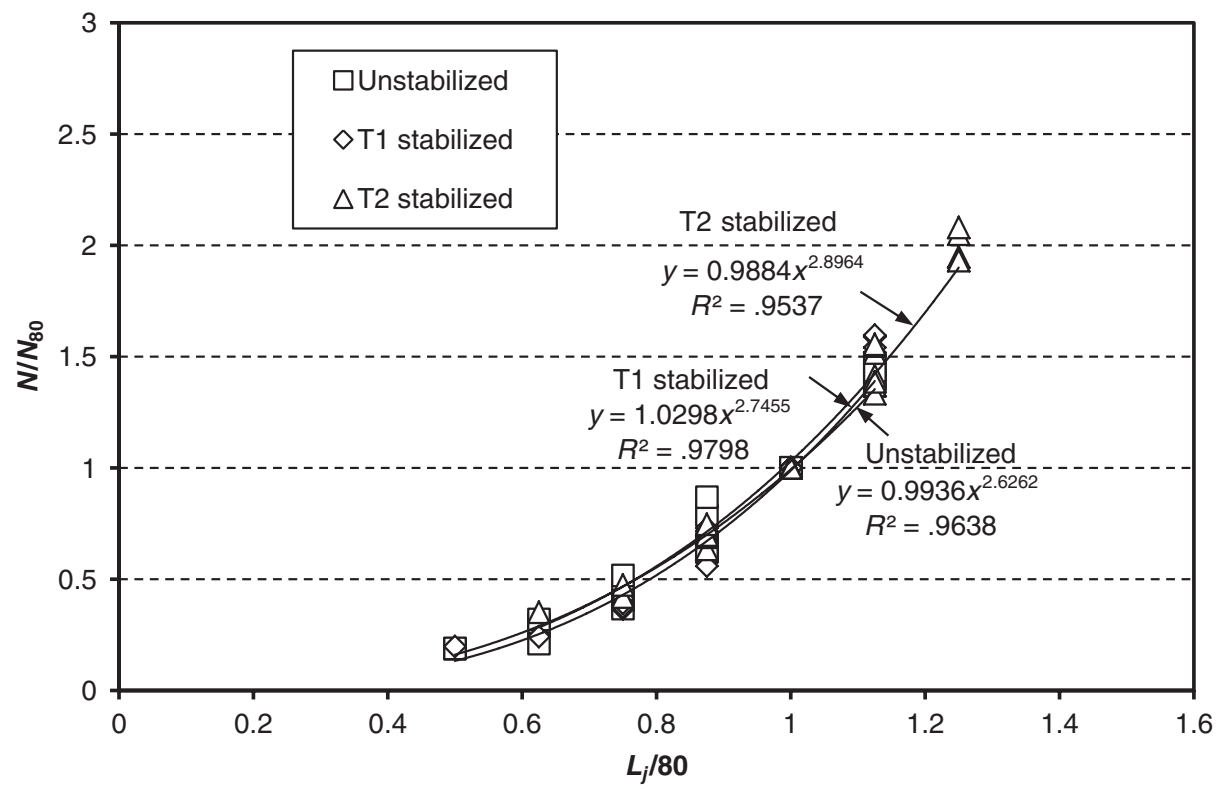

FIGURE 9 EALF versus $L_{j} / 80$ for test sections with different reinforcement types in terms of subgrade permanent deformation. 


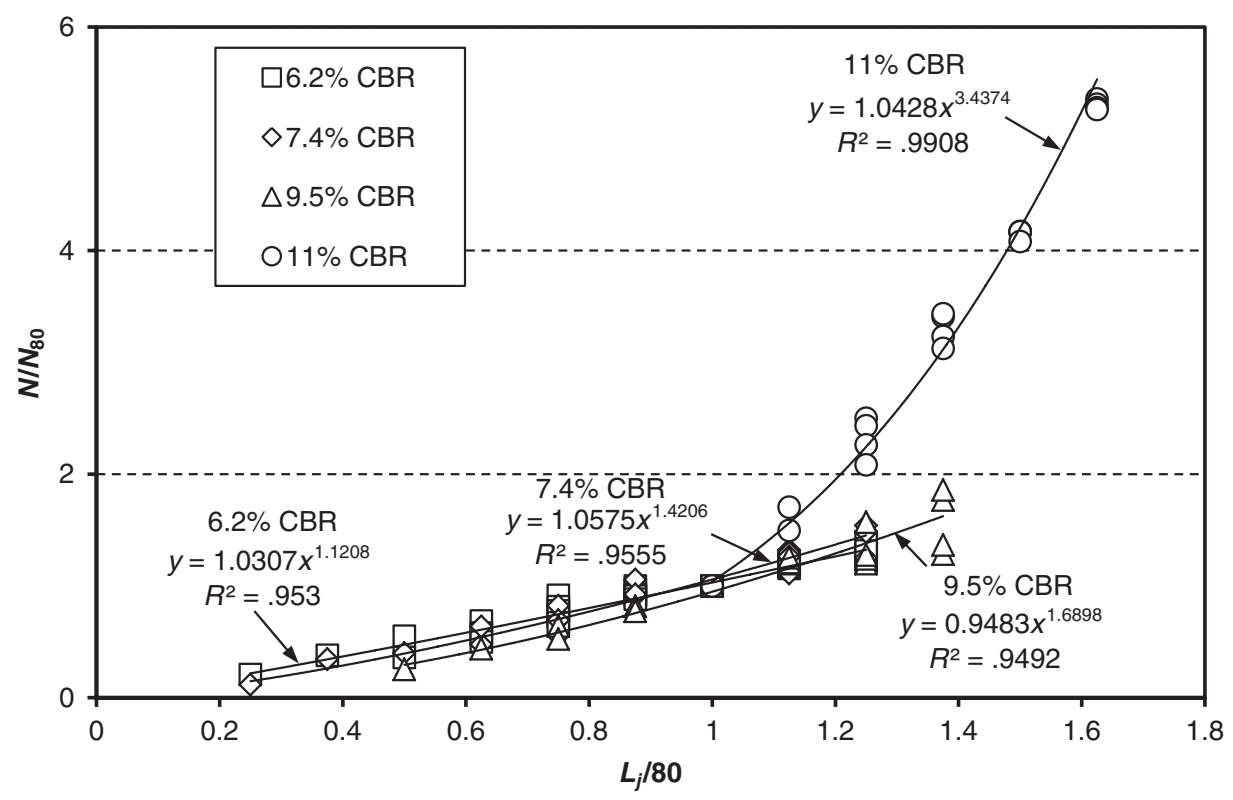

FIGURE 10 EALF versus $L_{j} / 80$ for test sections of subgrade with different CBRs in terms of surface permanent deformation.

ranged from 1.9 to 2.9. The increase of base thickness, the presence of the geogrid, and the use of the higher-grade geogrid increased the power $n$.

3. The powers $n$ of EALFs for the base courses over weak subgrade based on the subgrade permanent deformations were higher than those based on the surface permanent deformations.

4. The powers $n$ of EALFs for the subgrade-only sections with the CBR values from $6.2 \%$ to $11.0 \%$ ranged from 1.1 to 3.4 . The power $n$ depended on the CBR value of the subgrade. The subgrade with a higher CBR value had a larger $n$ value.

\section{ACKNOWLEDGMENTS}

This research was sponsored by Tensar International. Lee Crippen, an undergraduate research assistant, provided valuable assistance with the experimental tests conducted in this study.

\section{REFERENCES}

1. Deacon, J.A., F. Fin, W. Hudson, V.D. Obrcian, W. Hindermann, W. Warden, and C. Monismith. Load Equivalency in Flexible Pavements. Proceedings of the Association of Asphalt Paving Technologists, Vol. 38, 1969, pp. 465-494.

2. Huang, Y.H. Pavement Analysis and Design. Prentice Hall, Upper Saddle River, N.J., 1993.

3. Guide for Design of Pavement Structures, AASHTO, Washington, D.C., 1993.

4. Mechanistic-Empirical Pavement Design Guide, Interim Edition: A Manual of Practice. AASHTO, Washington, D.C., 2008.

5. Tran, N.H., and K. D. Hall. Development and Influence of Statewide Axle Load Spectra on Flexible Pavement Performance. In Transportation Research Record: Journal of the Transportation Research Board, No. 2037, Transportation Research Board of the National Academies, Washington, D.C., 2007, pp. 106-114.

6. Giroud, J.P., and L. Noiray. Geotextile-Reinforced Unpaved Road Design. Journal of the Geotechnical Engineering Division, Vol. 107, No. 9, 1981, pp. 1233-1254.
7. Yoder, E. J., and M.W. Witczak. Principles of Pavement Design. John Wiley, New York, 1975.

8. Dawson, A.R. Rut Accumulation and Power Law Models for LowVolume Pavements Under Mixed Traffic. In Transportation Research Record: Journal of the Transportation Research Board, No. 2068, Transportation Research Board of the National Academies, Washington, D.C., 2008, pp. 78-86.

9. Buhari, R., and S. Puteh. Damage Equivalent of the Flexible Pavement Variation with Load Applied. Applied Mechanics and Materials, Vol. 405, 2013, pp. 1917-1922.

10. Lin, P. S., Y.T. Wu, T. K. Huang, and C. Juang. Equivalent Single-Axle Load Factor for Rigid Pavements. Journal of Transportation Engineering, Vol. 122, No. 6, 1996, pp. 462-467.

11. Alabaster, D., J. De Pont, and B. Steven. The Fourth Power Law and Thin Surfaced Flexible Pavements. Proc., 9th International Conference on Asphalt Pavements, Copenhagen, Denmark, 2002.

12. Yeo, R., K. G. Sharp, S.L. Koh, and T.C. Martin. Load Damage Exponents for Thin Surfaced Granular Pavements. Proc., 3rd Accelerated Pavement Testing Conference, Minneapolis, Minn., 2004.

13. Tingle, J. S., and S. R. Jersey. Empirical Design Methods for GeosyntheticReinforced Low-Volume Roads. In Transportation Research Record: Journal of the Transportation Research Board, No. 1989, Vol. 2, Transportation Research Board of the National Academies, Washington, D.C., 2007, pp. 91-101.

14. Sun, X., J. Han, R. Parsons, M. Wayne, and J. Kwon. Quantifying the Benefit of Triaxial Geogrid in Stabilizing Granular Bases over Soft Subgrade Under Cyclic Loading at Different Intensities. Proceedings of the 2014 Geo-Congress, ASCE, Atlanta, Ga., 2014.

15. Pokharel, S. K. Experimental Study on Geocell-Reinforced Bases Under Static and Dynamic Loading. PhD dissertation. University of Kansas, Lawrence, Kans., 2010.

16. Dell' Acqua, G., M. De Luca, F. Russo, and R. Lamberti. Mix-Design with Low Bearing Capacity Materials. Baltic Journal of Road and Bridge Engineering, Vol. 7, No. 3, 2012, pp. 204-211.

17. Webster, S.L. Geogrid Reinforced Base Courses for Flexible Pavements for Light Aircraft: Test Section Construction, Behavior Under Traffic, Laboratory Tests, and Design Criteria. Technical Report GL-93-6. U.S Department of Transportation and Federal Aviation Administration, Washington, D.C., 1993.

The Committee for the 11th International Conference on Low-Volume Roads peer-reviewed this paper. 